\title{
As esmolas dos sobejos: Aspetos assistenciais da Régia Confraria de Nossa Senhora da Conceição de Vila Viçosa (1715-1750) The pittance of leftovers: Assistance aspects of the Régia Confraria de Nossa Senhora da Conceição de Vila Viçosa (1715-1750) \\ Francisco José Pegacha Pardal
}

Resumo: Em 1646, Nossa Senhora da Conceição de Vila Viçosa foi proclamada padroeira de Portugal por D. João IV. O culto litúrgico à padroeira foi assegurado pela Régia Confraria de Nossa Senhora da Conceição, que possuía avultados rendimentos. Uma pequena parte foi destinada às esmolas, tanto em trigo como em dinheiro. Os principais beneficiados foram as mulheres viúvas e órfãs, embora também tenham sido contemplados irmãos da confraria e alguns conventos.

Palavras-Chaves: Vila Viçosa; Imaculada Conceição; confraria; esmolas.

\begin{abstract}
In 1646, Our Lady of Conception of Vila Viçosa was proclaimed patroness of Portugal by king John IV. The liturgical service to the patroness was made by the Régia Confraria de Nossa Senhora da Conceição, which had big incomes. A small portion was allocated to alms, both in wheat and in money. The main beneficiaries were women widows and orphans, although confreres of brotherhood and some convents were also contemplated.
\end{abstract}

Keywords: Vila Viçosa; Immaculate Conception; brotherhood; pittance. 


\section{A Casa de Bragança}

\section{e a devoção à padroeira de Portugal}

A Imaculada Conceição foi uma das invocações de maior vulto no século XVIII, devendo-o ao facto de ser a padroeira do reino e de constar entre as devoções pessoais de D. João V (Braga, 2001: 121; Álvarez-Ossorio Alvariñom, 2017: 55-74). No entanto, a sua presença em Portugal é bem mais antiga, remetendo para o período medieval (Duque, 2013). Embora a Igreja tenha manifestado um parecer oficial sobre esta devoção muito tardiamente, sabe-se que colheu particular aceitação junto de diversos membros do clero e da nobreza medievais, tais como a rainha $\mathrm{D}$. Isabel de Aragão, os reis D. Duarte, D. Afonso V e D. João II (Pardal, 2018a: 31-36). Figura de grande relevo foi D. Nuno Álvares Pereira, que dedicou a igreja matriz de Vila Viçosa à Imaculada Conceição, no primeiro quartel do século XV (Espanca, 1892: 137). Do Condestável descendiam os duques de Bragança, pois o seu genro, D. Afonso, foi o primeiro detentor do título. Com o estabelecimento dos duques em Vila Viçosa, na segunda metade de quatrocentos, firmou-se uma estreita relação com Nossa Senhora da Conceição, à semelhança do que sucedia nas Cortes de Lisboa e de Madrid, nos séculos XVI e XVII (Pardal, 2018ª: 42-50).

No primeiro de dezembro de 1640 , o oitavo duque de Bragança foi feito rei de Portugal, como D. João IV. Pôs-se, assim, termo a sessenta anos de monarquia dual (Bouza, 2008; Olival, 2008; Oliveira, 2008). Deposto do trono português, Filipe IV procurou recuperar a coroa, levando a que houvesse vários confrontos na raia, durante os primeiros anos da década de 1640 (Costa e Cunha, 2008: 102). O mais expressivo foi a batalha do Montijo, travada em 1644, cuja vitória portuguesa trouxe alguma estabilidade à nova e frágil dinastia (Costa, 2004: 47-59). Ao darem-se passos tão promissores na sua consolidação no trono, o Restaurador teve em conta os conselhos que the haviam sido dados por D. Nuno da Cunha, reitor do colégio jesuíta de Coimbra (Pimentel, 1899: 244), e declarou Nossa Senhora da Conceição de Vila Viçosa padroeira de Portugal, em 25 de março de 1646 (Marques, 1983, I: 168). Cabe referir que a vila albergou a corte ducal até à Restauração (Costa e Cunha, 2008: 102).

O juramento teve lugar nas cortes do referido ano, tendo o soberano firmado numa provisão que cabia aos monarcas portugueses defender perpetuamente a crença na Imaculada Conceição (Sousa, 1740, VII: 206). D. João determinou também que seria pago um tributo anual de cinquenta cruzados à igreja matriz de Vila Viçosa, considerada a mais antiga daquela invocação na Península Ibérica (Sousa, 1740, VII: 206). Em 1648, o Restaurador estipulou que se cunhasse moeda com a efígie da padroeira, sendo os lucros remetidos para a localidade alentejana, como ajuda para a festa da Conceição (Castro, 1762, I: 181). Estes foram igualmente pagos pelos reis D. Afonso $\mathrm{VI}$ e D. Pedro II (Pardal, 2018a: 79). 
A devoção à padroeira de Portugal foi particularmente estimada na primeira metade do século XVIII. Durante grande parte do reinado de D. João V, entre 1715 e 1750, o soberano enviou anualmente esmolas no valor de 49.500 réis (APIMVV, RCNSCVV, 123: 44). 0 rei visitou a igreja calipolense duas vezes: a primeira, em 1716, com objetivo de pagar uma promessa; a segunda ocorreu em 1729, por ocasião dos duplos casamentos entre os herdeiros dos tronos português e espanhol com infantas dos respetivos reinos (Borges, 2017: 124-147). Ambos os casos refletem a estima tida pela família real à padroeira do reino.

\section{A Régia Confraria, alicerce da devoção imaculista}

Por ocasião da visita régia à igreja matriz de Vila Viçosa, gastaram-se 162.190 réis na ornamentação do templo, de forma a receber dignamente a Corte e a família real (APIMVV, RCNSCVV, 16: 44). A despesa foi suportada pela Régia Confraria de Nossa Senhora da Conceição, a mais antiga das duas irmandades imaculistas sediadas no referido templo (Melo, 1964: 7-8). Não se sabe ao certo quando foi fundada, pois embora a tradição considere que o seu fundador foi D. Nuno Álvares Pereira, os registos mais antigos remetem para o reinado de D.João II (Cunha, 2000: 381-382). Protegida pelos duques de Bragança (Cadornega, 1982: 24-26), contou com a estima dos reis brigantinos, que confirmavam os nomes dos mesários da irmandade (Araújo, 2001c: 131).
No que respeita ao universo confraternal calipolense, cabe referir que era pujante, sendo possível encontrar um elevado número de confrarias e irmandades. Embora tenhamos usado os dois termos num sentido equiparado, por questões estilísticas, esclareça-se que confrarias eram associações de fiéis com finalidades cultuais, espirituais e assistenciais, ao passo que a denominação irmandade se dedicada exclusivamente às pias uniões constituídas como corpo orgânico (Penteado, 2000: 459). A proliferação destas instituições deveu-se ao facto de Vila Viçosa ter sedeado a Corte dos duques de Bragança e de na localidade se terem fixado diversas ordens religiosas, nomeadamente as de São Francisco, Santo Agostinho, São Paulo e a Companhia de Jesus. Desta forma, onze igrejas e capelas, das muitas existentes na vila, albergavam 36 confrarias. O maior número tinha a sua sede na igreja matriz, por se tratar do principal templo local, assim como da paróquia de maior vulto, uma vez que a de São Bartolomeu perdera visibilidade quando deixou de ter sede própria (Araújo, 2000: 60-64).

Particularmente relevante foi a Misericórdia local, que já se encontrava em funcionamento em 1510, sendo duque de Bragança D. Jaime. Rapidamente a mesma ocupou um lugar de primazia na assistência aos mais desfavorecidos, tendo o referido titular brigantino colocado o já existente hospital do Espírito Santo sob a sua administração. É provável que aspetos assistenciais de irmandades anteriores 
à Santa Casa tenham transitado para a mesma (Araújo, 2000: 64). Tudo indica que the cabia a maior parte da ajuda aos pobres da vila, nomeadamente a atribuição de esmolas respeitantes a cereais, dinheiro roupa e cama, caso não possuíssem nada de seu e mendigassem pelas ruas (Araújo, 2000: 232). Tendo em conta que as restantes instituições se dedicavam, maioritariamente, a questões cultuais, não se descure o destaque que Régia Confraria de Nossa Senhora da Conceição alcançou na época moderna. A sua ação devocional remetia para o orago da localidade e também padroeira do reino, contando com a proteção da família real e das elites calipolenses. Era, por isso, uma confraria de elite e um meio de distinção social (Araújo, 2000: 60-64).

Voltemos aos mesários da Régia Confraria. Caso falecesse algum irmão, era sucedido pelo que se the seguia na lista de eleição, devendo o monarca ser informado dentro de um mês (Araújo, 2001c: 130). Os irmãos eram apologistas deste sistema, pois consideravam que esta era a melhor forma para gerir a confraria, procurando evitar cisões e outros aspetos nocivos à mesma (Araújo, 2001c: 130). Estes tinham de ser ricos, dignos e zeladores da fé católica (Araújo, 2001c: 131). O cargo mais importante cabia ao juiz, que devia zelar pelo bom funcionamento da irmandade. 0 escrivão, responsável por toda a documentação, deveria mantê-la atualizada. Ao tesoureiro, clérigo do hábito de São Pedro, cabia cuidar dos objetos do ornato da imagem da padroeira. Estava igualmente responsável pela cobrança das rendas em cuja função era auxiliado pelo andador (Araújo, 2001: 131).

Possuidora de um vasto património, desde terras de cultivo a habitações, consideramos que as peças para o ornato da imagem da Virgem Maria merecem particular destaque. Estas passaram por vestidos de Nossa Senhora da Conceição e do Menino Jesus, trémulas, mariposas, alfinetes, cordões e coroas de ouro, prata e gemas (Pardal, 2018b: 181-184). Grande parte destes objetos, de considerável valor, foram oferecidos entre 1719 e 1743 por importantes figuras da nobreza ou do clero. São significativos exemplos de que a matriz calipolense se tratava de um espaço devocional da Corte portuguesa (Pardal, 2018b: 184).

Tratando-se de uma confraria devocional, o culto religioso ocupou um lugar de destaque nas despesas da mesma. Todos os sábados se rezavam missas à padroeira, tendo estas custado 4.200 réis em 1718 e 14.400 réis, em 1743 (APIMVV, RCNSCVV, 11: 22). Pelo oitavário dos santos, esta era obrigada a mandar rezar três ofícios - onde se despendiam 3.000 réis (APIMVV, RCNSCVV, 14: 19). A festa de 8 de dezembro parece ter tido particular relevância para a referida irmandade. Contava com missa cantada, sermão e procissão pelas ruas da vila, sendo a igreja ornada para o efeito (Braga, 1992: 455-468; Gouveia, 2000, I-P: 334-337). Tenha-se em 
conta que a expressividade da devoção à padroeira se enquadrava nas reformas levadas a cabo no século XVI e que marcaram a confessionalização católica na época moderna. Assim sendo, importar frisar que as figuras de Cristo e da Virgem Maria adquiriram particular relevância, de modo a que a piedade cristológica e mariana resultasse em práticas cultuais mais evocativas e abstratas (Palomo, 2006: 93).

De acordos com os estatutos de 1696, a Régia Confraria de Nossa Senhora da Conceição tinha o dever de auxiliar os confrades na hora da morte, promovendo, assim, a solidariedade entre os mesmos. Além disso, propunha-se a distribuir esmolas pelos mais necessitados, nomeadamente trigo por 30 pobres da vila, particularmente viúvas e órfãs, pelo Natal. A proveniência destas ofertas remetia para as rendas fixas da confraria - nomeadamente os pagamentos em trigo - e para os peditórios realizados na véspera da solenidade da padroeira. Embora este aspeto assistencial se devesse ao facto de a localidade ser pobre e existirem desfavorecidos que necessitassem desse apoio, aos quais a Misericórdia nem sempre conseguia chegar, os mesmos só tinham lugar quando o culto não absorvia a totalidade dos rendimentos. Por outras palavras, a devoção à Imaculada Conceição tinha precedência nos gastos da confraria (Araújo, 2001: 135).

Houve, durante a época moderna, pobres que pediram auxílio a irmandades, de modo a serem beneficiados com as esmolas que estas distribuíam. Assim sucedeu com a Irmandade do Santíssimo Sacramento de Santo Estêvão de Alfama, em Lisboa: entre 1806 e 1820, foram feitas 294 petições (Braga, 2014: 13). No caso da Régia Confraria de Nossa Senhora da Conceição de Vila Viçosa, não se conhece nenhuma referência a pedidos. Sabe-se que esta atribuiu esmolas a mulheres pobres de Vila Viçosa, o que, aliás, vai de acordo ao que foi estipulado no compromisso de 1696 (Araújo, 2001c: 135). Entregues por altura do Natal, eram provenientes das rendas da irmandade e do peditório que esta fazia pela vila (Araújo, 2001c: 135). Desta forma, a referência a esta prática assistencial foi comum nos itens dos livros de receita e despesa. No que respeita a esta questão, propomos uma leitura do gráfico I:

Gráfico I: Esmolas de trigo que a Régia Confraria de Nossa Senhora da Conceição entregou a mulheres pobres de Vila Viçosa

(1716-1749)

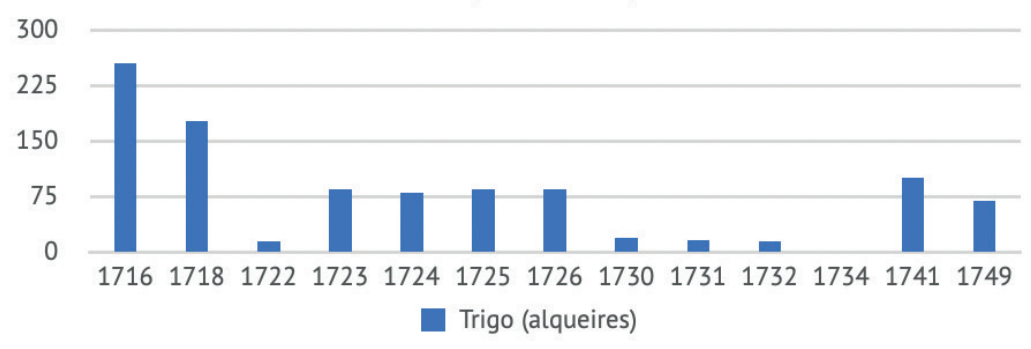

Fonte: APIMVV, RCNSCVV, 18, 19, 20, 21, 22, 23, 24, $25,26,27,28$ e 29. 
Os dados referentes às esmolas de trigo revelam que estas não abarcaram todos os anos que nos propusemos estudar, muito provavelmente por os rendimentos da confraria terem sido canalizados para despesas litúrgicas. Nos anos em que este aspeto figurou entre os gastos da irmandade, as maiores quantias foram concedidas em 1716, 1718 e 1741, no valor de 256, 178 e 54 alqueires, respetivamente (APIMVV, RCNSCVV, 11: 22-57; 23: 89-91v). Os números foram exponencialmente menores em anos como o de 1722 - 15 alqueires - ou de 1734 - três alqueires -, o que não menoriza a importância que o trigo oferecido teve junto das mulheres carentes da localidade alentejana. No entanto, as descrições dos itens evidenciam um caráter geral, não sendo raro encontrar os seguintes exemplos: «D[espendi] com as esmollas que esta confraria mandou dar este anno a veuvas e donzelas pobres e nessecitadas»; «D[espendi] com algumas pessoas honradas» ou «D[espendi] com algumas pessoas honradas e recolhidas» (APIMVV, RCNSCVV, 18: 41). Veja-se, em seguida, os casos concretos de atribuição de esmolas.

\section{As esmolas concedidas pela Régia Confraria de Nossa Senhora da Conceição}

O Arquivo Paroquial da Igreja Matriz de Vila Viçosa conserva várias dezenas de livros de receita e despesa da irmandade em estudo, a maioria deles respeitante aos séculos XVIII,
XIX e XX. Para a primeira centúria referida, os registos mais antigos remetem para o ano de 1715 e não se verificaram falhas até ao fim do reinado de $D$. João $V$, à exceção de 1747 (APIMVV, RCNSCVV: 11-29). Embora a festa de Nossa Senhora da Conceição e as celebrações litúrgicas a que a confraria estava obrigada correspondam à maioria dos gastos, não podemos deixar de notar que vários itens remetem para a outorga de esmolas, tanto em dinheiro como em alqueires de trigo.

Na época moderna, a caridade era sinónimo de amor a Deus (Lopes, 1999, I: 48-51) e as confrarias desempenharam um papel relevante nas questões assistenciais (Abreu, 1992: 3-15; Penteado, 2000, A-C: 459-470; Araújo, 2001; Idem, 2001: 359-378; Gomes, 2002; Reis, 2005; Coutinho e Ferreira, 2004: 201-215; Santos, 2005; Pulido Serrano, 2006: 20-51; Oliveira, 2009: 509-530; Beirante, 2011; Braga, 2014: 1-19). No caso da Régia Confraria de Nossa Senhora da Conceição, esta deveria auxiliar os seus confrades na doença e na morte, tendo-se estipulado no novo compromisso que se venderiam as mortalhas oferecidas à padroeira para se comprarem as dos irmãos defuntos (Araújo, 2001c: 130-135).

Não abundaram os casos que reportam para a assistência da irmandade junto dos confrades, sendo que o maior beneficiário foi o andador Manuel Gonçalves e a sua família: em 1730 e em 1736, o assalariado da confraria esteve doente, tendo esta contribuído com 240 e 
800 réis, respetivamente, para o seu tratamento (APIMVV, RCNSCVV: 17: 85); em 1735, por falecimento de uma filha, recebeu 800 réis para fazer o enterro (APIMVV, RCNSCVV, 18: 101); em 1739, por doença da mulher, despenderam-se 1.440 réis (APIMVV, RCNSCVV, 22: 53), gastando-se 530 em 1742 com a mesma (APIMVV, RCNSCVV, 23: 29).

Em casa de Manuel Gonçalves, vivia Micaela de Jesus, escrava que o padre Manuel Vieira deixou em testamento à guarda da confraria. A escravatura foi uma prática comum durante a época moderna e as instituições religiosas possuíam alguns escravos (Fonseca, 2002; Henriques, 2009; Caldeira, 2017), embora a confraria apenas mantivesse os que os padres deixaram aos seus cuidados (APIMVV, RCNSCVV, 23: 9). No que diz respeito a Micaela de Jesus, a irmandade contribuía para o seu sustento com 2.400 réis anuais, pagos em duas quantias de 1200 réis, entre 1741 e 1750 (APIMV, RCNSCVV, 23: 39; 24: 51; 26: 50-57; 27: 59; 28: 47-53; 29: 40-46). Outras esmolas foram outorgadas pela Régia Confraria, sem, no entanto, haver referência ao tipo de carência. Em 1727, despenderam-se 1.200 réis numa esmola não identificada, sucedendo o mesmo no ano seguinte, com o valor de 1.800 réis. Em 1736, foi concedida uma outra, de 800 réis, ao passo que a de 1740 correspondeu a 60 réis. Três anos depois, o juiz recebeu uma esmola não especificada no valor de 480 réis, tendo o mesmo decidido que se entregasse a mesma quantia a um estudante de Vila Viçosa que frequentava o curso de medicina, em 1746 (APIMVV, RCNSCVV, 16: 16-43; 18: 94; 21: 71; 24: 53; 27: 50).

Outra vertente das esmolas da Régia Confraria de Nossa Senhora da Conceição está relacionada com a assistência a vários espaços conventuais alentejanos. A mais antiga data de 1731, quando foram enviados dez alqueires de trigo ao convento de Santa Helena do Monte Calvário, em Évora (APIMVV, RCNSCVV, 18: 19). Esta casa de religiosas franciscanas foi fundada em 1565 pela infanta D. Maria, filha de D. Manuel I e de D. Leonor de Habsburgo. Desse ano datou a autorização de D. João de Melo, arcebispo de Évora, para a sua construção, sendo que a inauguração só ocorreu em 1574. O convento do Calvário fomentou a devoção a Nossa Senhora da Conceição, pois nele existia um quadro da mesma invocação, datando este do final do reinado de D. João V (Espanca, 1966, VII: 241-245).

Em 1733, foi enviada a primeira esmola ao convento de Nossa Senhora do Carmo, em Moura, no valor de 1200 réis (APIMVV, RCNSCVV, 18: 59). Fundado no século XIII por cavaleiros da Ordem de São João do Hospital, foi bastante dotado pelos reis de Portugal, nomeadamente D. João I, D. João III e D. Sebastião e tido em grande conta por D. Nuno Álvares Pereira (Santa Maria, 1718, VI: 246-253). O último espaço conventual a beneficiar das esmolas da Régia Confraria foi o recolhimento de Santa Marta de Évora, recebendo a quantia 
de 120 réis, em 1740 (APIMVV, RCNSCVV,21:70). A sua fundação remonta a 1490, em casas doadas pela família dos Estaços. No século XVI, foi protegido por D. Francisco de Portugal, conde de Vimioso, que custeou as suas obras de ampliamento (Espanca, 1966, VII: 238). 0 auxílio concedido a conventos e recolhimentos expressou-se tanto em dinheiro como em alqueires de trigo, coexistindo os dois tipos de esmola no mesmo ano. Sobre a atribuição destas esmolas, importa referir que não se tratava de um caso singular na época moderna, uma vez que a pobreza e o défice de rendimentos marcavam o quotidiano de conventos e recolhimentos. Muitos destes espaços encontravam-se endividados para manter um funcionamento regular, contribuindo este tipo de esmolas para colmatar as suas constantes necessidades. Refira-se, a título de exemplo, que o convento do Calvário era um dos mais pobres do Alentejo, no século XVIII (Subtil, 2011: 65-72).

De acordo com os dados do Quadro I (em anexo), é possível afirmar que o maior beneficiário por parte da Régia Confraria de Nossa Senhora da Conceição foi o convento de Santa Helena do Monte Calvário, pois entre 1731 e 1749 recebeu 7.920 réis e 16,5 alqueires de trigo. Houve anos em que este espaço conventual foi contemplado com esmolas monetárias e cerealíferas, como os de 1741 e de 1742 (APIMVV, RCNSCVV, 23: 83-89; 24: 34-51), tendo em conta que a primeira categoria chegou a corresponder a mais do que um item: em 1736, a confraria enviou uma esmola de 480 e duas de 800 réis (APIMVV, RCNSCVV, 23: 83-89; 19: 94-95). No segundo quartel do século XVIII, o convento de Nossa Senhora do Carmo gozou de menor número de donativos, num total de 2.360 réis e 7,5 alqueires, verificando-se que, também no caso mourense, coexistiram as duas tipologias de esmola no mesmo ano, nomeadamente em 1734 (APIMVV, RCNSCVV, 23: 83-89; 18: 86-92). Como anteriormente se referiu, o RecoLhimento de Santa Marta foi contemplado com uma única esmola, em 1740, no valor de 120 réis (APIMVV, RCNSCVV, 83: 83-99; 21: 70).

No que respeita a referências a viúvas e órfãs que beneficiaram das esmolas da confraria, referidas no ponto 2 deste estudo, a exceção às descrições acima citadas prende-se com o ano de 1741, pois o escrivão da confraria, António Luís de Melo, discriminou os nomes e a condição social das figuras femininas que beneficiaram de vários alqueires de trigo (APIMVV, RCNSCVV, 12: 71; 18: 19-92; 23: 89-91v). As mulheres da época moderna eram maioritariamente camponesas pobres, mal alimentadas, malvestidas e com poucos cuidados higiénicos, tanto em Portugal como na Europa. Contrariamente ao que muitas vezes se refere, a atividade laboral feminina não se circunscrevia ao ambiente doméstico, já que muitas mulheres eram jornaleiras, criadas rurais, agricultoras de terra própria ou criadoras de gado (Ribeiro, 2013: 122-123; Lopes, 2015: 1770-1771). Embora 
tivessem um papel na economia familiar, a sua fragilidade evidenciava-se em caso de viuvez ou de orfandade. Eram mais vulneráveis à pobreza e, por essa razão, não se estranhe a assistência domiciliária a que se encontravam sujeitas, quer pela necessidade de criar os filhos, quer por ter ocorrido a desestruturação do agregado familiar, por doença ou morte do cônjuge (Pardal, 2015: 237-243). Em relação à confraria caliponense, o surgimento dos nomes dessas mulheres parece estar em sintonia com os casos da já referida Irmandade do Santíssimo Sacramento de Santo Estêvão de Alfama, assim como da Confraria de Nossa Senhora da Guia de Ponte de Lima. No primeiro caso, registaram-se os nomes, a idade, o sexo e a condição social dos requerentes de inícios do século XIX (Braga, 2014: 13-18), enquanto o segundo remete essencialmente para o nome e a morada dos confrades (Araújo, 2001-2002: 443-448).

Atente-se o quadro II, em anexo, no que diz respeito ao caso de Vila Viçosa. Dos 101,5 alqueires de trigo entregues em 1741, 54 foram cedidos a 37 viúvas, 18 a cerca de 13 órfãs, havendo ainda outros casos, que abordaremos adiante (APIMVV, RCNSCVV, 23: 89-91v). Desconhecemos o motivo da concessão da esmola por parte da irmandade, podendo estes casos estar relacionados com idade avançada, doença ou incapacidade de garantir o próprio sustento - assim sucedeu com as beneficiadas pela Irmandade do Santíssimo Sacramento de Santo Estêvão de Alfama (Braga, 2014: 13-18).
A pobreza pode ser confirmada pela morada de algumas mulheres: Catarina Rodrigues, Maria Rodrigues e Francisca Maria, viúvas, e as órfãs de João Rodrigues Martelo residiam no castelo, um dos bairros mais pobres de Vila Viçosa durante o século XVIII (Araújo, 2000: 30). No caso das três órfãs de Manuel Cordeiro Vinagre, sabe-se que a família passou por diversas dificuldades, pois este pediu 50.000 réis a juro à Régia Confraria, e, por seu falecimento, os herdeiros não conseguiram suportar tão avultado encargo (Pardal, 2018a: 352).

Houve casos em que as órfãs o eram apenas de pai, pois contavam com a companhia da mãe: assim sucedeu com Beatriz Tomásia, viúva, que residia com as duas filhas na Rua de António Homem e beneficiou de três alqueires de trigo (APIMVV, RCNSCVV, 23: 91). Maria Teresa e Catarina de São Miguel, também órfãs, viviam em casa de Isabel Dias «a Bordala», sita na Rua dos Gentis, e receberam dois alqueires e meio de trigo em 1741 (APIMVV, RCNSCVV, 23: 91). Houve também casos de mulheres que partilhavam a mesma habitação: Isabel e Catarina Madeira, moradoras no Pátio das Chagas, receberam dois alqueires de esmola (APIMVV, RCNSCVV, 23: 91).

Maria Rodrigues e Beatriz Rodrigues, que residiam numa casa da Rua dos Fidalgos, aceitaram os dois alqueires que a irmandade thes concedeu (APIMVV, RCNSCVV, 23: 91). Houve certamente casos de mulheres abonadas que 
caíram em desgraça: presume-se que tal sucedeu com Margarida de Oliveira, viúva do Doutor Francisco Xavier Ferreira, residente na Rua das Vaqueiras, recetora de dois alqueires e meio de trigo (APIMVV, RCNSCVV, 23: 90). Jerónima de Oliveira pode ter estado em situação semelhante, pois o seu marido, Manuel de Almeida, foi alferes de cavalaria e a sua viúva necessitou de uma esmola da confraria de dois alqueires de trigo (APIMVV, RCNSCV, 23: 91v).

No referido ano de 1741, a Régia Confraria entregou dois alqueires e meio a Ana Maria de Abreu, moradora na Rua da Corredoura (APIMVV, RCNSCVV, 23: 89v). Esta era irmã do padre Manuel de Abreu e, possivelmente, ficou sem rendimentos com a morte do eclesiástico (APIMVV, RCNSCVV, 23: 89v). Era comum, na época moderna, os padres deixarem os seus bens às igrejas ou irmandades a que estavam ligados (Goulart, 2007: 381-383). A referida Ana Maria poderia estar aos cuidados da confraria, embora nos pareça mais plausível tratar-se de um caso de pobreza (APIMVV, RCNSCVV, 23: 89v). Incomum na assistência da irmandade foi o envio de um alqueire de trigo a Maria Falarda (APIMW, RCNSCVV, 23: 90). António Luís de Melo referiu que a mesma era ermitoa em São Bento, levando-nos a crer que viveria junto da ermida do mesmo nome, apesar de as fontes não o esclarecerem. $\mathrm{Na}$ verdade, o templo calipolense situava-se num alto, junto ao Paço do Reguengo e ao Forte de Caracena, tendo sido fundado pelos duques de Bragança no século XVI (Espanca, 1978, IX: 603). Foi reformado no início do século XVIII, cabendo a iniciativa ao tabelião Silvestre Mendes e a Manuel Vieira Velho, capelão da Colegiada de São Jerónimo (Espanca, 1978, IX: 603).

Apesar da expressividade que as esmolas tiveram junto dos calipolenses carenciados, estas não diziam respeito às despesas de primeira ordem da irmandade (Pardal, 2018a: 178-191). É possível agrupar os rendimentos da Régia Confraria discriminados nos Quadros III e IV, em anexo da seguinte forma: os mais importantes em dinheiro, seguindo-se os géneros, em trigo e em azeite (Pardal, 2018a: 178-191). No que respeita ao grupo monetário, cabe referir que, em 1727, da venda de medidas e da bacia resultaram 79.770 réis; das esmolas dos devotos e das rendas da capela instituída pelo padre Paulo Correia Velho, 75.000; das esmolas enviadas por D. João V, 73.500; e do auferido através de aforamentos e de juros, 51.503 (Pardal, 2018a: 248). Em 1738, a maior fatia resultou da venda de trigo (139.320), seguindo-se as esmolas régias (67.250), a venda de medidas e as esmolas da bacia (33.840), os aforamentos e juros (12.500) e as rendas da capela do padre Paulo (1.500) (Pardal, 2018a: 253).

Em 1746, a receita monetária passou pelos seguintes aspetos: esmolas régias (67.000), trigo vendido (51.897,5), esmolas dos devotos e rendas da capela (26.766), foros e juros (5.530), 
venda de medidas e esmolas da bacia (4.800) (Pardal, 2018a: 257). No caso do trigo, as receitas de alqueires advieram maioritariamente do pagamento de foros (em 1727, 273,5; em 1738, 395; em 1746, 340,5) (Pardal, 2018a: 263-269). No que diz respeito às despesas da confraria, a maior fatia coube a aspetos relacionados com o culto litúrgico: despesas com padres e músicos (em 1727, 77.280; em 1738, 44.280; em 1746, 78.718), manutenção da igreja e festa de Nossa Senhora da Conceição (em 1727, 11.650; em 1738, 45.160; em 1746, 22.985), missas dos sábados e ofícios pelo oitavário dos Santos (em 1727, 3.800; em 1738, 39.360; em 1746, 26.210) (Pardal, 2018a: 248-257). Esta centralidade cultual não foi caso único na confraria em estudo, pois irmandades como a do Santíssimo Sacramento de Veiros canalizaram o grosso dos seus rendimentos para estas questões (Oliveira, 2016: 266-267).

As esmolas concedidas tiveram uma importância residual, pois os dados de 1727, 1738 e 1746 não surgiram por acaso: em nenhum dos referidos anos foram concedidas esmolas em trigo, as de maior vulto no caso da Régia Confraria (APIMVV, RCNSCVV, 16: 31; 22: 19; 27: 25). As despesas remetem para confeção de bolinhos oferecidos na festa da padroeira (12 alqueires), e de hóstias para as missas (2 alqueires), no que respeita ao ano de 1727 (Pardal, 2018a: 263). Volvidos onze anos, a situação foi idêntica: empregaram-se seis alqueires nos bolinhos e dois nas hóstias (Pardal, 2018a. 263).
Em 1746, ano em que as receitas estiveram em queda, o item da despesa remete unicamente para 38 alqueires de trigo vendido, situação comum quando a irmandade tinha dificuldades em suportar as despesas monetárias (Pardal, 2018a: 269). Esta situação vai de encontro à política de aplicação de verbas da Régia Confraria, nomeadamente aos gastos com as esmolas, pois, de acordo com os estatutos de 1696 , estas só deveriam ser entregues após estarem asseguradas as questões cultuais (Araújo, 2001: 135). Justifica esta determinação o facto de as esmolas não serem intensivas nem uma despesa de maior peso. Era privilegiada a devoção à Imaculada Conceição, por sinal padroeira do reino (Araújo, 2001: 135).

\section{Em jeito de conclusão}

A devoção à Imaculada Conceição foi verdadeiramente expressiva após a chegada da casa de Bragança ao trono. Ligados a Vila Viçosa, os monarcas brigantinos engrandeceram a referida invocação, orago da localidade alentejana. Segundo os livros de receita e despesa da Régia Confraria de Nossa Senhora da Conceição de Vila Viçosa, respeitantes ao reinado de $D$. João $V$, foram entregues esmolas em dinheiro e em trigo. Entre 1731 e 1749, três espaços conventuais alentejanos foram contemplados com algumas quantias monetárias ou com alguns alqueires de trigo.

O compromisso de 1696 estipulou que cabia à irmandade cuidar dos confrades na doença 
e na morte, embora a documentação apenas mencione que, na primeira metade de Setecentos, apenas o andador e a sua família recorreram a esse serviço. Não se descarte a hipótese de os confrades terem sido auxiliados, mediante peditórios realizados entre os mesmos e cuja receita não constava nos registos. A cargo da irmandade estava também uma escrava, Micaela de Jesus, que ficou aos cuidados da mesma por determinação do seu antigo proprietário, um eclesiástico.

Verdadeiramente significativas foram as esmolas em trigo, entregues a diversas mulheres pobres de Vila Viçosa. Apenas em 1741 estas figuraram nos registos de forma discriminada, o que permitiu apurar que a maioria das beneficiadas foram viúvas, seguindo-se as órfãs. O escrivão anotou a morada das necessitadas calipolenses, o nome dos pais ou do defunto marido, tendo sido possível apurar que as esmolas não foram inferiores a meio alqueire de trigo, nem superiores a cinco alqueires. Houve outros casos menores e pontuais, como esmolas não identificadas, uma esmola entregue ao juiz ou o auxílio que a irmandade prestou a um estudante da vila que cursava medicina.

Desta forma, as questões assistenciais da estavam dependentes dos rendimentos da instituição. Assim sendo, podemos considerar os donativos de esmolas de sobejos concedidos pela confraria, pois só existiam quando as prioridades cultuais eram asseguradas. No entanto, apesar de estas estarem secundarizadas, a sua importância foi notória, procurando essencialmente suprir a fome das mulheres pobres e colmatar lacunas em espaços conventuais que constantemente padeciam com dificuldades financeiras.

\section{Anexos}

Quadro I: Esmolas entregues pela Régia Confraria de Nossa Senhora da Conceição aos conventos do Calvário e do Carmo e ao recolhimento de Santa Marta (1731-1749)

\begin{tabular}{|c|c|c|c|c|c|c|}
\hline & \multicolumn{2}{|c|}{ Convento do Calvário } & \multicolumn{2}{|c|}{ Convento do Carmo } & \multicolumn{2}{|c|}{ Recolhimento Sta. Marta } \\
\hline & $\begin{array}{c}\text { Esmola } \\
\text { em dinheiro }\end{array}$ & $\begin{array}{l}\text { Esmola } \\
\text { em trigo }\end{array}$ & $\begin{array}{c}\text { Esmola } \\
\text { em dinheiro }\end{array}$ & $\begin{array}{l}\text { Esmola } \\
\text { em trigo }\end{array}$ & $\begin{array}{c}\text { Esmola } \\
\text { em dinheiro }\end{array}$ & $\begin{array}{l}\text { Esmola } \\
\text { em trigo }\end{array}$ \\
\hline 1731 & & 10 alqueires & & & & \\
\hline 1733 & 480 réis & & 1200 réis & & & \\
\hline 1734 & & & 240 réis & 1,5 alqueires & & \\
\hline 1735 & & 3 alqueires & & 2 alqueires & & \\
\hline 1736 & 1280 réis & & & & & \\
\hline 1737 & 480 réis & & 800 réis & & & \\
\hline 1738 & 480 réis & & & & & \\
\hline 1739 & 400 réis & & & 2 alqueires & & \\
\hline 1740 & 480 réis & & 120 réis & & 120 réis & \\
\hline 1741 & 480 réis & 1,5 alqueires & & 2 alqueires & & \\
\hline 1742 & 480 réis & 2 alqueires & & & & \\
\hline
\end{tabular}




\begin{tabular}{c|c|c|c|c|c|c} 
& \multicolumn{2}{|c|}{ Convento do Calvário } & \multicolumn{2}{c|}{ Convento do Carmo } & \multicolumn{2}{c}{ Recolhimento Sta. Marta } \\
\cline { 2 - 7 } & $\begin{array}{c}\text { Esmola } \\
\text { em dinheiro }\end{array}$ & $\begin{array}{c}\text { Esmola } \\
\text { em trigo }\end{array}$ & $\begin{array}{c}\text { Esmola } \\
\text { em dinheiro }\end{array}$ & $\begin{array}{c}\text { Esmola } \\
\text { em trigo }\end{array}$ & $\begin{array}{c}\text { Esmola } \\
\text { em dinheiro }\end{array}$ & $\begin{array}{c}\text { Esmola } \\
\text { em trigo }\end{array}$ \\
\hline 1743 & 480 réis & & & 2 alqueires & & \\
\hline 1744 & 480 réis & & & & & \\
\hline 1745 & 480 réis & & & & & \\
\hline 1746 & 480 réis & & & & & \\
\hline 1748 & 480 réis & & & & & \\
\hline 1749 & 480 réis & & & & & \\
\hline
\end{tabular}

Fonte: APIMVV, RCNSCVV, 18, 19, 20, 21, 22, 23, 24, 25, 26, 27, 28 e 29.

Quadro II: Número de esmolas de trigo concedidas a mulheres pobres e honradas de Vila Viçosa, pela Régia Confraria de Nossa Senhora da Conceição (1741)

\begin{tabular}{|c|c|c|c|}
\hline Nome & Morada & Estado matrimonial & Esmola \\
\hline Inácia Antónia & Rua do Poço & $\begin{array}{c}\text { Solteira e órfã de Filipe dos Santos } \\
\text { e de Rosa Maria }\end{array}$ & 2 \\
\hline Antónia de Figueiredo & Rua de Santa Luzia & Viúva & 3 \\
\hline Maria Martins & Aldeia dos Bugios & Viúva & 1 \\
\hline Bárbara Siqueira & Desconhecida & Viúva & 1 \\
\hline Paula Gomes & Aldeia dos Bugios & Viúva de Manuel Soares Santinhos & 2 \\
\hline Joana da Silva & Rua das Pedras & Viúva de Simão da Silva e Vaz & 2 \\
\hline Ana Maria de Abreu & Rua da Corredoura & Irmã do Padre Manuel de Abreu & 2 \\
\hline Catarina Mendes & Rua da Torre & Viúva de Leonardo Rodrigues & 1 \\
\hline Maria Mendes & Rua das Vaqueiras & Viúva de Manuel de Matos & 1 \\
\hline Catarina Lopes Fartel & Rua de Santa Luzia & Viúva de Pedro Dias Fartel & 2 \\
\hline Francisca Rodrigues & Rua de Santa Luzia & Viúva & 2 \\
\hline
\end{tabular}




\begin{tabular}{|c|c|c|c|}
\hline Nome & Morada & Estado matrimonial & Esmola \\
\hline Catarina Rodrigues & Castelo & Viúva de António Rodrigues Siqueira & 1 \\
\hline Josefa Maria & Rua da Freira & Viúva & 1 \\
\hline Desconhecido & Rua de Santa Luzia & $\begin{array}{l}\text { Solteiras. Três órfãs, } \\
\text { filhas de Manuel Cordeiro Vinagre }\end{array}$ & 3 \\
\hline Catarina Gonçalves & Rua dos Gentis & Viúva de Gabriel da Silva & 2 \\
\hline Margarida de Oliveira & Rua das Vaqueiras & Viúva de Francisco Xavier Ferreira & 2 \\
\hline Ana Maria & Rua das Vaqueiras & $\begin{array}{c}\text { Viúva. Filha de Pedro Martins Pardal, } \\
\text { «Jumento Velho» }\end{array}$ & 2 \\
\hline Maria Rodrigues & Castelo & Viúva de Inácio de Siqueira & 1 \\
\hline Mariana Leda & Rua dos Caldeireiros & Viúva de João Gomes & 4 \\
\hline Maria Falarda & Desconhecido & Eremitoa de São Bento & 1 \\
\hline Joana da Silva & Rua da Praça & Viúva de Francisco Mendes & 1 \\
\hline Catarina Mendes & Rua dos Fidalgos & Desconhecida & 2 \\
\hline Rosa Maria & Rua dos Fidalgos & Viúva de José Martins & 1 \\
\hline Antónia Rosa & Rua das Vaqueiras & Viúva & 1 \\
\hline Ana Maria & Rua de Três & Viúva de José Monteiro & 2 \\
\hline Francisca Xavier & Rua de Três & Viúva de Francisco Lopes & 1 \\
\hline Maria Teresa & Rua da Freira & Viúva de Lourenço Nunes, «o Mestre» & 1 \\
\hline
\end{tabular}




\begin{tabular}{|c|c|c|c|}
\hline Nome & Morada & Estado matrimonial & Esmola \\
\hline Maria Gomes & Rua da Freira & Viúva de Manuel Fernandes, «o Boino» & 1 \\
\hline Desconhecido & Castelo & Órfãs de João Rodrigues Martelo & 1 \\
\hline Joana Franca & Rua de Três & Viúva & 1 \\
\hline Ana Gomes & Rua das Cortes & Viúva & 1 \\
\hline Maria Dias, «a Parteira» & Desconhecida & Viúva & 2 \\
\hline Maria Furtiva & Rua de D. Pascoela & Viúva & 1 \\
\hline Maria Rodrigues & Rua dos Fidalgos & Viúva & 1 \\
\hline Beatriz Rodrigues & Rua dos Fidalgos & Companheira de Maria Rodrigues & 1 \\
\hline Maria Correia & Rua da Praça & Desconhecida & 1 \\
\hline $\begin{array}{c}\text { Isabel Madeira e Catarina } \\
\text { Madeira }\end{array}$ & Pátio das Chagas & Viúvas. Eram irmãs & 2 \\
\hline Maria Franca e uma sobrinha & Adro de... (?) & Viúva de António Ledo. Sobrinha órfã & 2 \\
\hline $\begin{array}{c}\text { Beatriz Tomásia e duas filhas } \\
\text { órfãs }\end{array}$ & Rua de António Homem & Viúva/ órfãs & 3 \\
\hline Beatriz de Torres & Rossio de S. Paulo & Desconhecida & 2 \\
\hline $\begin{array}{c}\text { Maria Teresa e Catarina de S. } \\
\text { Miguel }\end{array}$ & Rua dos Gentis & $\begin{array}{l}\text { Órfãs. Moradoras em casa de Isabel Dias, } \\
\qquad \text { «a Bordala» }\end{array}$ & 2 \\
\hline Maria do Rosário & Rua das Cortes & Desconhecida & 2 \\
\hline Desconhecido & Rossio de S. Paulo & Órfãs de Manuel Marinho & 3 \\
\hline
\end{tabular}




\begin{tabular}{c|c|c|c} 
Nome & Morada & Estado matrimonial & Esmola \\
Ana Maria & Aldeia de... (?) & Viúva de Domingos Vinagre & 1 \\
Maria Micaela & Rossio & Viúva de Nuno Vidal & 1 \\
\hline Catarina Rosada & Desconhecida & Viúva de Manuel Gonçalves & 1 \\
\hline Francisca Maria & Castelo & Viúva de Manuel de Almeida & 2 \\
\hline \multirow{2}{*}{ Jerónima de Oliveira } & Desconhecida & &
\end{tabular}

Quadro III: Receita e despesa monetária da Régia Confraria de Nossa Senhora da Conceição de Vila Viçosa (1727-1738-1746)

\begin{tabular}{|c|c|c|c|c|c|c|c|}
\hline Receita (réis) & 1727 & 1738 & 1746 & Despesa (réis) & 1727 & 1738 & 1746 \\
\hline $\begin{array}{c}\text { Foros/ } \\
\text { rendas/juros }\end{array}$ & 51.503 & 12.500 & 5.530 & $\begin{array}{l}\text { Andador/ } \\
\text { armador }\end{array}$ & 29.740 & 12.980 & 7.470 \\
\hline Esmolas régias & 73.500 & 67.250 & 67.000 & Azeite & 20.120 & 45.000 & 15.100 \\
\hline $\begin{array}{c}\text { Esmolas/ } \\
\text { Rendas da capela }\end{array}$ & 75.000 & 1.500 & 26.766 & $\begin{array}{l}\text { Questões } \\
\text { jurídicas }\end{array}$ & 3.380 & 74.110 & 7.960 \\
\hline $\begin{array}{c}\text { Medidas/ } \\
\text { Bacia }\end{array}$ & 79.770 & 33.840 & 4800 & $\begin{array}{l}\text { Fitas para } \\
\text { medidas }\end{array}$ & 81.970 & 27.500 & - \\
\hline Trigo vendido & 51.800 & 139.320 & 51.898 & Padres/músicos & 77.280 & 44.280 & 78.718 \\
\hline Ano anterior & 364.125 & 102.768 & 46.346 & Missas e ofícios & 3.800 & 39.360 & 26.210 \\
\hline \multirow[t]{3}{*}{ Outros } & & & & $\begin{array}{c}\text { Manutenção } \\
\text { da igreja }\end{array}$ & 11.650 & 45.160 & 22.985 \\
\hline & & & & Outros & 11.490 & 10.730 & 1.670 \\
\hline & 695.698 & 357.178 & 202.340 & Total & 239.970 & 299.120 & 160.113 \\
\hline
\end{tabular}

Fonte: APIMVV, RCNSCVV, 16, 22, 27 
Quadro IV: Receita e despesa cerealífera da Régia Confraria

de Nossa Senhora da Conceição de Vila Viçosa (1727-1738-1746)

\begin{tabular}{|c|c|c|c|c|c|c|c|}
\hline Receita (alqueires) & 1727 & 1738 & 1746 & Despesa (alqueires) & 1727 & 1738 & 1746 \\
\hline Foros/rendas & 273,5 & 395 & 340,5 & Andador/Bolinhos & 12 & 6 & 49 \\
\hline Esmolas & 7 & & 14 & Hóstias & 2 & 2 & 2 \\
\hline \multirow[t]{2}{*}{ Outros } & & & 157 & Esmolas & & & \\
\hline & & & & Trigo vendido & & & 119 \\
\hline Total & 280,5 & 395 & 511,5 & Total & 14 & 8 & 170 \\
\hline
\end{tabular}

Fonte: APIMVV, RCNSCVV, 16, 22, 27

\section{Bibliografia}

\section{Manuscrita}

Arquivo Paroquial da Igreja Matriz de Vila Viçosa (APIMVV), Régia Confraria de Nossa Senhora da Conceição de Vila Viçosa (RCNSCVV), $11,12,13,14,15,16,17,18,19,20,21,22,23$, 24, 25, 26, 27, 28, 29, 123.

\section{Impressa}

Abreu, L. (1991). Confrarias e irmandades de Setúbal: Redes de sociabilidade. Atas do I Congresso Internacional do Barroco. Reitoria da Universidade do Porto, Governo Civil do Porto. Porto. 1. ${ }^{\circ}$ vol: pp. 3-15;

Alvariño, A.Á.-O. (2017). «iQuieren los españoles definir!»: La Inmaculada Concepción y la monarquía de España durante el siglo XVII. Em: P. Tornel (ed.). Intacta María. Política y religiosidad en la España barroca. Museo de Bellas Artes de Valencia. Valencia;

Araújo, M.M.L. de (2000). Dar aos pobres e emprestar a Deus: As misericórdias de Vila Viçosa e Ponte de Lima (séculos XVI-XVIII). Santa Casa da Misericórdia de Ponte de Lima. Ponte de Lima; Araújo, M.M.L. de (2001a). A confraria de São Pedro da Gafanhoeira, entre a aurora e o entardecer. Cadernos do Noroeste: Série História, 15 (2): 359-378;
Araújo, M.M.L. de (2001b). A Confraria do Santíssimo Sacramento do Pico dos Regalados (1731-1780). Associação de Desenvolvimento das Terras Altas do Homem, Cávado e Ave. Vila Verde;

Araújo, M.M.L. de (2001c). Servir a dois senhores: A Real Confraria de Nossa Senhora da Conceição de Vila Viçosa através dos seus estatutos de 1696. Callipole, 9: 127-139;

Araújo, M.M.L. de (2001-2002). A ajuda aos pobres nas confrarias de Nossa Senhora da Guia e do Espírito Santo de Ponte de Lima (séculos XVII a XIX). Bracara Augusta, 50: 441-468;

Beirante, M.Â. (2011). As antigas confrarias da Vila de Cabeção: Espelho da sua vida social. Edição da Autora. S. L.;

Borges, S.A.F. (2017). Duas cortes, um modelo: O cerimonial diplomático nas relações luso-espanholas (1715-1750). Tese de Mestrado em História das Relações Internacionais. Faculdade de Letras, Universidade de Lisboa. Lisboa. 237 pp.;

Bouza, F. (2008). D. Filipe I. Temas \& Debates. Lisboa;

Braga, I.M.R.M.D. (1992). Entre o sagrado e o profano: As procissões em Portugal no século XVIII segundo alguns relatos de estrangeiros. 
Em: M.H. Santos (coord.). A festa. Universitária Editora. Lisboa. 2. ${ }^{\circ}$ vol.;

Braga, I.M.R.M.D. (2012). A Irmandade do Santíssimo Sacramento de Santo Estêvão de Alfama e a assistência à pobreza (1806-1820). Revista Tempo, 20: 1-19;

Braga, P.D. (2001). Igreja, igrejas e culto. Em: J. Serrão e A. Marques (dirs.) e A. de Menezes (coord.). Nova História de Portugal. Editorial Presença. Lisboa. 7. ${ }^{\circ}$ vol.;

Cadornega, A. de O. de (1982). Descrição de Vila Viçosa. Imprensa Nacional-Casa da Moeda. Lisboa;

Caldeira, A.M. (2017). Escravos em Portugal. Das origens ao século XIX. A Esfera dos Livros. Lisboa;

Castro, J.B. de (1762). Mappa de Portugal antigo e moderno. Oficina Patriarcal de Francisco Luiz Ameno. Lisboa. 1. ${ }^{\circ}$ vol.;

Costa, F.D. (2004). A Guerra da Restauração, 1641-1668. Livros Horizonte. Lisboa;

Costa, L.F. e Cunha, M.S. da (2008). D. João IV. Temas \& Debates. Lisboa;

Costa, S.G. (2007). Viver e morrer religiosamente. Ilha de São Miguel, século XVIII. Instituto Cultural de Ponta Delgada. Ponta Delgada;

Coutinho, M.J.P. e Ferreira, S. (2004). As irmandades da Igreja de São Roque: Tempo, propósito e legado. Revista Lusófona de Ciência das Religiões, 3 (5-6): 201-215;

Cunha, M.S. da (2000). A Casa de Bragança, 1560-1640: Práticas senhoriais e redes clientelares. Editorial Estampa. Lisboa;

Duque,J.F. (2013). O fuso e a trama. Cosmorama Edições. Maia;

Espanca,J.J. da R. (1892). Compêndio de notícias de Villa Viçosa concelho da província do Alemtejo e reino de Portugal. Tipografia de Francisco de Paula Oliveira de Carvalho. Redondo;

Espanca, T. (1966). Inventário artístico de Portugal. Concelho de Évora, VII. Academia Nacional de Belas-Artes. Lisboa. 1. ${ }^{\circ}-2{ }^{\circ}$ vols.;
Espanca, T. (1978). Inventário artístico de Portugal. Distrito de Évora. Concelhos de Alandroal, Borba, Mourão, Portel, Redondo, Reguengos de Monsaraz, Viana do Alentejo e Vila Viçosa, IX. Academia Nacional de Belas Artes. Lisboa;

Faria, F.L. de (1984). Crença e culto da Imaculada Conceição em Portugal. Revista Española de Teología, 44 (1): 137-160;

Fonseca, J. (2002). Escravos no sul de Portugal, séculos XVI-XVII. Editora Vulgata. Oeiras;

Gomes, P.A. de C.S. (2002). Oficiais e confrades em Braga no tempo de Pombal (contributos para o estudo do movimento e organização confraternal bracarenses no século XVIII). Tese de Mestrado em História. Instituto de Ciências Sociais, Universidade do Minho. Braga. 251 pp.;

Gouveia, A.C. (2000). Procissões. Em: C.M. de Azevedo (dir.) e J.F. Marques e A.C. Gouveia (coords.). História religiosa de Portugal. Círculo de Leitores. Lisboa. 2. ${ }^{\circ}$ vol.;

Henriques, I.C. (2009). A herança africana em Portugal. Clube do Colecionador dos Correios. Lisboa;

Lopes, M.A. (1999). Pobreza, assistência e controlo social em Coimbra (1750-1850). Tese de Doutoramento em História Moderna e Contemporânea. Faculdade de Letras, Universidade de Coimbra. Coimbra;

Maduell, À. (1992). Ramon Llull, teòleg de la Immaculada. Studia Lulliana, 32: 163-180;

Marques, J.F. (1983). A parenética portuguesa e a Restauração. Tese de Doutoramento em História Moderna e Contemporânea. Faculdade de Letras, Universidade do Porto. Porto. 627 pp.;

Marques, J.F. (2000). Oração e devoções. Em: C.M. de Azevedo (dir.) e J.F. Marques e A.C. Gouveia (coords.). História religiosa de Portugal. Círculo de Leitores. Lisboa. $2 .^{\circ}$ vol.;

Meirinhos, J.F. (2008). No sétimo centenário do teólogo e filósofo João Duns Escoto. Em: J.F. Meirinhos (coord.). João Duns Escoto (1265-1308). Subsídios bibliográficos. Gabinete de Filosofia Medieval da Faculdade de Letras da Universidade do Porto. Porto; 
Melo, A.P.M. (1964). As históricas confrarias concepcionistas de Vila Viçosa. Armas e Troféus, 2 (5): 5-12;

Olival, F. (2008). D. Filipe II. Temas \& Debates. Lisboa;

Oliveira, A. (2008). D. Filipe III. Temas \& Debates. Lisboa;

Oliveira, R.P. de (2009). Para o estudo da Irmandade de São Pedro Mártir no final do século XVIII. Actas do IV Congresso Histórico de Guimarães "Do Absolutismo ao Liberalismo». Câmara Municipal de Guimarães. Guimarães. pp 509-530;

Oliveira, R.P. de (2016). A Irmandade do Santíssimo Sacramento de Veiros, nos finais do Antigo Regime. Lusitania Sacra, 33 (2): 266-267;

Pardal, F.J.P. (2018a). Uma devoção de grandes e pequenos: Nossa Senhora da Conceição de Vila Viçosa nos séculos XVII e XVIII. Tese de Mestrado em História, especialização em História Moderna e Contemporânea. Faculdade de Letras, Universidade de Lisboa. Lisboa. 407 pp.;

Pardal, F.J.P. (2018b). Um espaço devocional da corte portuguesa: A Igreja de Nossa Senhora da Conceição de Vila Viçosa (séculos XVII e XVIII). Librosdelacorte.es, 17: 169-189;

Penteado, P. (2000). Confrarias. Em: C.M. Azevedo (dir.). Dicionário de História de Portugal. Círculo de Leitores. Lisboa. Vol. A-C;
Pimentel, A. (1899). História do culto de Nossa Senhora em Portugal. Livraria Guimarães. Libânio e Companhia. Lisboa;

Reis, M. de F. (2005). Santarém no tempo de D. João V: Administração, sociedade e cultura. Edições Colibri. Lisboa;

Santa Maria, A. de (1707-1723). Santuário mariano e história das imagens milagrosas de Nossa Senhora e das milagrosamente apparecidas, em graça dos prégadores, \& devotos da mesma Senhora, que compreende as imagens de Nossa Senhora, que se venerão na corte, e cidade de Lisboa, I-X. Oficina de António Pedrozo Galram. Lisboa. 1. ${ }^{\circ}-9 .^{\circ}$ vols.;

Santos, G.S. dos (2005). Ofício e sangue. A Irmandade de São Jorge e a Inquisição na Lisboa moderna. Edições Colibri, Instituto de Cultura Ibero-Atlântica. Lisboa;

Serrano, J.I.P. (2006). Hermandades portuguesas fuera de Portugal (siglos XVI-XVIII). Em: M.G. Ventura (coord.). $O$ associativismo. Das confrarias e irmandades aos movimentos sociais contemporâneos. Edições Colibri, Instituto de Cultura Ibero-Americana. Lisboa;

Sousa, A.C. (1740). História genealógica da Casa Real Portuguesa. Régia Oficina Silviana. Lisboa. 7. ${ }^{\circ}$ vol. 